\title{
Indoor transmission dynamics of expired SARS-CoV-2 virus in a model African hospital ward
}

\author{
Jamiu Adetayo Adeniran ${ }^{1,2}$ (I) - Ishaq Alhassan Mohammed ${ }^{1} \cdot$ Oladele Idris Muniru $^{3} \cdot$ Taofeek Oloyede $^{4}$. \\ Omowonuola Olubukola Sonibare ${ }^{5} \cdot$ Muhammad-Najeeb O. Yusuf $^{1} \cdot$ Khadijat Abdulkareem Abdulraheem $^{6}$. \\ Emmanuel Tolulope Odediran ${ }^{1} \cdot$ Rafiu Olasunkanmi Yusuf $^{1} \cdot$ Jacob Ademola Sonibare $^{7}$
}

Received: 16 September 2020 / Accepted: 15 December 2020 / Published online: 22 January 2021

(C) Springer Nature Switzerland AG 2021

\begin{abstract}
Cough and sneeze droplets' interactions with indoor air of a typical hospital clinic that could be majorly found in developing African countries were studied to investigate the effectiveness of existing guidelines/protocols being adopted in the control of the widespread coronavirus disease (COVID-19) transmission. The influences of indoor air velocity, the type, size distribution, residence time in air, and trajectory of the droplets, were all considered while interrogating the effectiveness of physical distancing measures, the use of face covers, cautionary activities of the general public, and the plausibility of community spread of the SARS-CoV-2 virus through airborne transmission. Series of 3-D, coupled, discrete phase models (DPM) were implemented in the numerical studies. Based on DPM concentration maps as function of particle positions and particle residence times that were observed under different droplets release conditions, the virus-laden droplets could travel several meters away from the source of release (index patient), with smaller-sized particles staying longer in the air. The behavior of indoor air was also found to indicate complex dynamics as particle transports showed no linear dependence on air velocity.
\end{abstract}

Keywords Covid-19 $\cdot$ SARS-CoV-2 $\cdot$ Airborne transmission $\cdot$ Indoor environment $\cdot$ Aerosols

Jamiu Adetayo Adeniran

adeniranja@pku.edu.cn; adeniran.ja@unilorin.edu.ng

1 Environmental Engineering Research Laboratory, Department of Chemical Engineering, University of Ilorin, Ilorin, Nigeria

2 Laboratory for Climate and Ocean-Atmosphere Studies, Department of Atmospheric and Oceanic Sciences, School of Physics, Peking University, Beijing 100871, China

3 Department of Biomedical Engineering, University of Ilorin, Ilorin, Nigeria

4 Department of Internal Medicine, Federal Medical Centre, Katsina, Katsina State, Nigeria

5 Department of Family Medicine, General Out Patient Department, Obafemi Awolowo Teaching Hospital Complex (OAUTHC), Ile-Ife, Osun State, Nigeria

6 Department of Civil Engineering, University of Ilorin, Ilorin, Nigeria

7 Environmental Engineering Research Laboratory, Department of Chemical Engineering, Obafemi Awolowo University, Ile-Ife, Nigeria

\section{Introduction}

As of 10:00 am Central European Summer Time, 16 September 2020, about 29,611,346 cases of corona virus disease (COVID-19), including 935,929 deaths had been reported globally since December 2019 [1], creating severe burden on the healthcare system [2]. From these alarming figures, the United States of America had had the highest reported cases $(6,606,859)$, and about $4.587 \%(1,358,238)$ of the total cases had occurred in Africa, with South Africa taking the lead in the continental catastrophe at the time [1]. The incidence of increasing daily new cases has raised concerns about the various modes of transmission of the severe acute respiratory syndrome coronavirus 2 (SARS-CoV-2), popularly known as the COVID-19 virus [2,3]. The SARS-CoV-2 has been found to be transmissible amongst people, primarily through respiratory droplets (i.e. coughing or sneezing) and contact routes (fomites) [4], with possibility of its airborne transmission through aerosols [4]. Though whether SARS-CoV-2 can be transmitted by aerosols remains controversial $[2,5]$, the environmental and microclimatic conditions in indoor settings cannot be ignored in abating viral infections like the COVID- 
19, especially as it relates to aerosols. Previous studies have demonstrated that microclimatic parameters and concentration of emitted aerosols from indoor sources influence human exposure [6-8]. Indeed, adequate understanding of the extent of environmental contamination of SARS-CoV-2 is essential for improving safety practices for essential workers and answering questions about SARS-CoV-2 transmission among the public [2].

Research findings are becoming available about the airborne transmission of SARS-CoV-2 [9], especially in specific circumstances and settings such as in procedures or support treatments that generate aerosols [4]. It has been observed in a study that the coronavirus may spread not just by sneezes or coughs, but also via mere talking or possibly even by just breathing, when aerosolized droplets are produced during these activities [9]. The bioaerosols of coronavirus droplets generated directly by patients' exhalation could remain suspended in the air and potentially infect someone who walks by later. Though airflow conditions in the outdoor environments are able to disperse the virus, large droplets would deposit close to their source of release, and smaller droplets carrying the virus could be found in the indoor locations more than 6 feet [9], or 13 feet (about $4 \mathrm{~m}$ ) [2] away from the patients. Moreover, in theory, influenza viruses can be transmitted through aerosols, large droplets, or direct contact with secretions (or with fomites), and these three modes are not mutually exclusive [10]. Reviewed reports had also suggested that the previously known SARS-CoV can potentially be transmitted by short and long-range aerosols to cause disease [11-16]. Recently, Morawska and Cao have maintained that the SARS-CoV-2 virus is likely to be spreading through the air, and small droplets exhaled by an infected person could travel tens of meters in the air [5] thus, air control measures are being suggested [17-19].

While the potential for aerosol transmission of SARS$\mathrm{CoV}-2$ is not fully understood, it also remains unclear the absolute maximum distance that a virus-laden fluid particle can travel and how the concentration of these particles varies spatially and temporally [17]. In this contribution, computational fluid dynamics study of the 200-400 nm - sized SARSCoV-2 virus was carried out, to investigate the possibility of its airborne transmission. In doing this, procedures were followed similar to those reported in previous studies that had successfully implemented the computational methods to predict the transmission of infectious diseases such as the Sverdlovsk anthrax outbreak of 1979, foot-and-mouth disease, severe acute respiratory syndrome (SARS) virus, TB bacteria, and others [4, 20-24] by using discrete phase models (DPM). The study suggests that the general hospital settings of indoor patients' bed-spacing in developing countries may not be adequate, and airborne transmission of SARS-CoV-2 virus, in aerosolized form, may be contributing to the spread of COVID-19. It could be a matter of airflow dynamics.

\section{Methods}

\section{Motivation for choice of computational fluid dynamic models}

The SARS-CoV-2 virus responsible for COVID-19 is genetically similar to other coronaviruses, sharing a high degree of genetic similarity $-79 \%$ identity [25] with the coronavirus responsible for severe acute respiratory syndrome (SARS$\mathrm{CoV})$. Therefore, in instances of limited evidence for COVID-19, it is reasonable to extrapolate existing data from other coronaviruses, in particular SARS-CoV [26]. Specifically, computational models using studies of airflow dynamics have been successfully applied to investigate the airborne transmission of the SARS virus, in which threedimensional spread of a virus-laden aerosol plume was considered, and its correlation was examined with data of temporal and spatial distribution of cases [14].

\section{The DPM models of SARS-CoV-2}

The phenomenon of airborne transmission of droplets in air is a type of multiphase flow problem that can be well-defined by the DPM model in ANSYS Fluent. In the present study, series of coupled, steady-state discrete phase model (DPM) simulations were carried out in ANSYS Fluent on a local machine in parallel processing mode. The three-dimensional layout of the hospital ward setting, created in Space claim design modeler (SCDM) is presented in Fig. 1.

In the model, a hospitalized infected patient lying on his back in bed coughed/sneezed upwardly (sometimes, sideways) was assumed as the index patient. The upward release has rarely been studied in most previous works, and slower transport of cough/sneeze droplets may be expected considering the impacts of gravity on the initial speed of release of parcels, and hence the simulation results of concentrations obtained could mean lowest transmission case scenarios. Worse cases of droplets transport should occur in patients releasing droplets (cough/sneezes) in the direction of air travel especially in walking position. The simulation was designed to answer a number of questions bordering around the airborne transmission of SARS-CoV-2 and results are presented in the following subsections in terms of DPM concentrations with respect to the $\mathrm{x}$-direction (across the hospital ward) westeast wise.

The realizable $\mathrm{k}-\varepsilon$ turbulence model with standard wall functions in Fluent was used to model the effects of turbulence on airflow and aerosols transport. Coupled DPM method allows interaction of discrete phase (droplets) with the continuous phase (air) during solution iterations, and hence the calculation of DPM concentrations of virus-laden aerosols indoor. A summary of input parameters used in the computational study is presented in Table 1. 
Fig. 1 The hospital ward setting showing (a) a six-bed layout, with the droplets source clearly identified (where the index patient lying on a bed could cough or sneeze upwards or sideways), and (b) the meshing
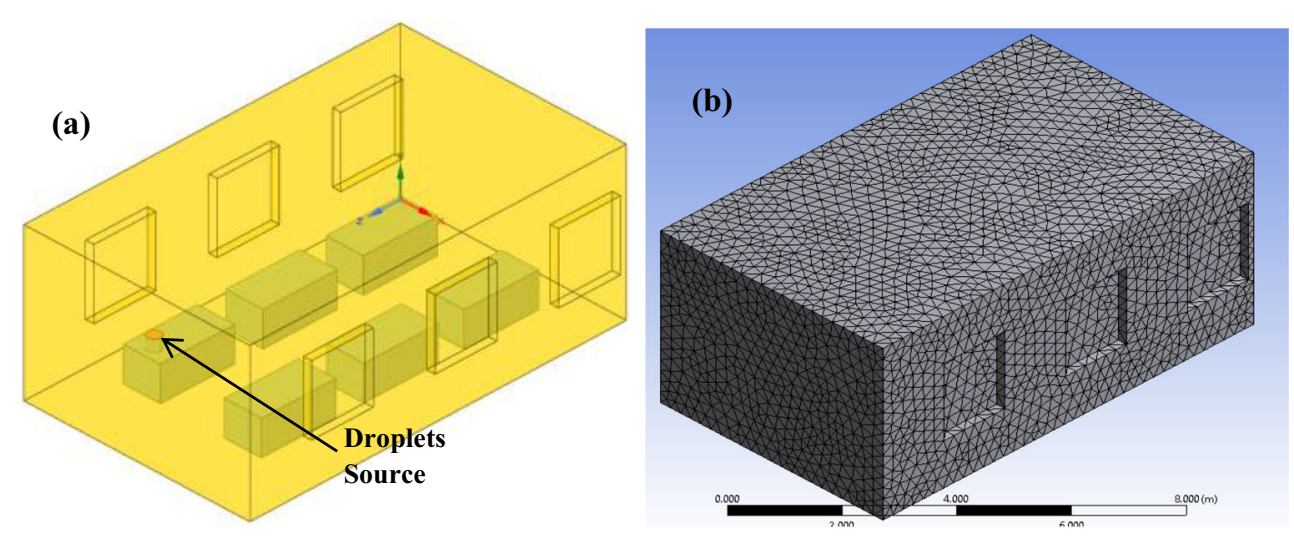

\section{The DPM theory}

In DPM, the trajectories of particles, droplets or bubbles are computed in a Lagrangian frame. The particles can exchange heat, mass, and momentum with the continuous gas phase. Each trajectory represents a group of particles, all with the same initial conditions. The DPM simulation models the air as the continuous phase and the cough or sneeze droplets as the discrete phase. The air comes in through windows on one side of the building as defined, and leaves through the windows on the opposite wall. The cough or sneeze source was from an index patient, with location in the ward as defined. Findings from this work can as well apply to all public gatherings and public places such as the shared offices, public transports, restaurants, classrooms, places of worship, market places, shopping malls or supermarkets. To compute the DPM concentration in ANSYS Fluent, it is calculated by defining the DPM concentration as given in Eq. (1);

DPMconcentration $=\frac{(\text { Avg.particlemassincell } \times \text { ParticleresidenceTime } \times \text { Strengthofparticle })}{\text { Cellvolume }}$

where, the strength of particle is defined as (Eq. 2a,b):

Strength of particle $=\frac{\text { number in parcel }}{d t_{\text {flow }}}$

$$
=\frac{\text { total particle flow rate }}{\text { mass of single particle in the stream }}
$$

In Eq. (2a), dt flow is change in flow. Therefore, from Eq. (1) and Eq. (2b), it follows that:

$D P M$ conc. $=\frac{(\text { Avg. particle mass in cell } \times \text { Part resi. Time } \times \text { Total particle flow rate })}{(\text { mass of single particle in stream } \times \text { cell volume })}$

The DPM concentration maps (x-y plots) were therefore considered convenient as easy to interpret, and was used together with the DPM concentration contours to present the particle transport behaviors in the indoor environment.

\section{Results and discussion}

\section{Indoor environmental conditions: air velocity}

The indoor environmental parameters such as the humidity, temperature, or air flow rate are important in dealing with droplets and aerosol transports vis-à-vis the transmission of infectious diseases like the COVID-19. As shown in Fig. 2, the air velocity was found to have impact on the transmission of SARS-CoV-2 virus either via cough droplets or sneezes. The air velocity impact $(1,2,3,4,5$ and $6 \mathrm{~m} / \mathrm{s})$ was investigated for cough droplets (3000 parcels) and sneezes (40,000 parcels), at flow rate of $1 \mathrm{~kg} / \mathrm{s}$ and relative velocities of $(10 \mathrm{~m} / \mathrm{s}, 100 \mathrm{~m} / \mathrm{s})$, respectively.

Cough droplets were released upwards, and sneezes were released sideways in the positive $\mathrm{x}$-direction. Based on the one-dimensional path length (along x-position) shown in Fig. 2, some sneeze droplets from infected persons could reach 
Table 1 Summary of input parameters for CFD analysis

\begin{tabular}{|c|c|c|c|}
\hline \multirow[t]{2}{*}{1.} & \multicolumn{3}{|l|}{ Room Features } \\
\hline & & Room dimensions & $30 \mathrm{ft} \times 18 \mathrm{ft} \times 14 \mathrm{ft}$ \\
\hline \multirow[t]{6}{*}{2.} & Sneeze flow properties & & \\
\hline & & Sneeze material & Liquid water droplets \\
\hline & & Relative velocity of sneeze & $100 \mathrm{~m} / \mathrm{s}(16)$ \\
\hline & & Particle size distribution & $0.5-12 \mu \mathrm{m}(16)$ \\
\hline & & Flow rate & $1 \mathrm{~kg} / \mathrm{s}$ \\
\hline & & Number of parcels & $40,000(16)$ \\
\hline \multirow[t]{6}{*}{3.} & Cough flow properties & & \\
\hline & & Cough material & Liquid water droplets \\
\hline & & Relative velocity of cough & $10 \mathrm{~m} / \mathrm{s}(23)$ \\
\hline & & Particle size & 0.31 microns $(23)^{*}$ \\
\hline & & Flow rate & $1 \mathrm{~kg} / \mathrm{s}$ \\
\hline & & Number of parcels & 3000 \\
\hline \multirow[t]{2}{*}{4.} & Air flow characteristics & & \\
\hline & & Air velocity & $1-6 \mathrm{~m} / \mathrm{s}$ \\
\hline
\end{tabular}

*The corona virus is reported to have size in the range $200-400 \mathrm{~nm}(0.20-0.40 \mu \mathrm{m})$
$4.6 \mathrm{~m}$ within a fraction of a second after release from source. Though with non-linear complex dynamics, the path lengths traveled by droplets was observed to have changed directions randomly in the $x-y-z$ axes at higher air velocities due to turbulence (large Reynolds number), and thus was generally reduced in the X-direction. Increased turbulence caused complex particles dynamics which made particles traveled in all directions. The higher velocities are considered representative of forced convection, and the results would imply that keeping physical distance under normal indoor (natural convection air flow) should be considered different from indoor settings which generate forced air currents such as the AC systems or similar operations. Supporting the air turbulence-influenced complex particle dynamics are the 3-D plume and DPM concentration maps presented in supporting information $(\mathrm{S} 1-\mathrm{S} 4)$, and Fig. 3a - for sneezes, and Fig. 3b - for cough droplets.

\section{Face masks efficiency: are textile masks able to prevent transmission?}

Common surgical masks and their equivalent textile types are now widely used in Africa in various styles to reduce the risk of SARS-CoV-2 infection. These face covers are able to reduce the immediate release of original virus-laden aerosols, but they are not $100 \%$ efficient in preventing the transmission of droplets from coughs or sneezes [23]. Another issue with the use of nose masks is the danger of $\mathrm{CO}_{2}$ poisoning as persons on nose masks for too long could inhale their own exhaled $\mathrm{CO}_{2}$ from breathing. However, what has been studied in this work is the efficiency of masks in preventing the transmission of droplets from infected persons. It can be inferred from Fig. 4 that barriers such as masks are able to reduce the concentration of virusladen cough droplets depending on the mask efficiency.
Fig. 2 Air velocity impact on virus-laden sneezes and cough droplets

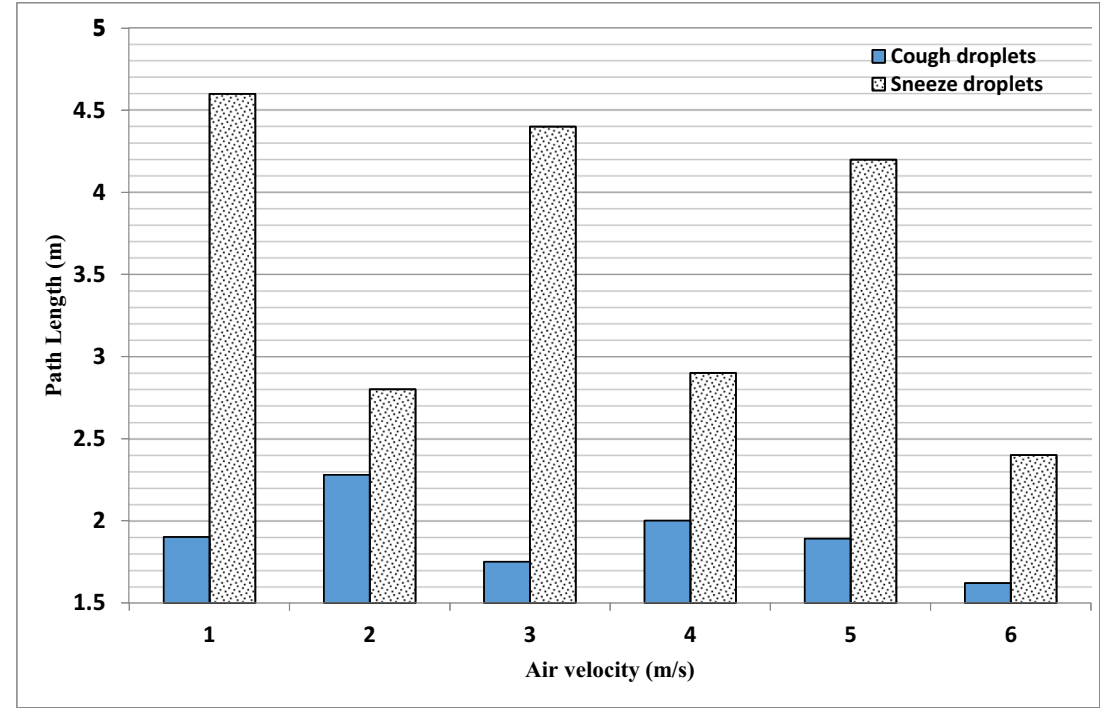


a
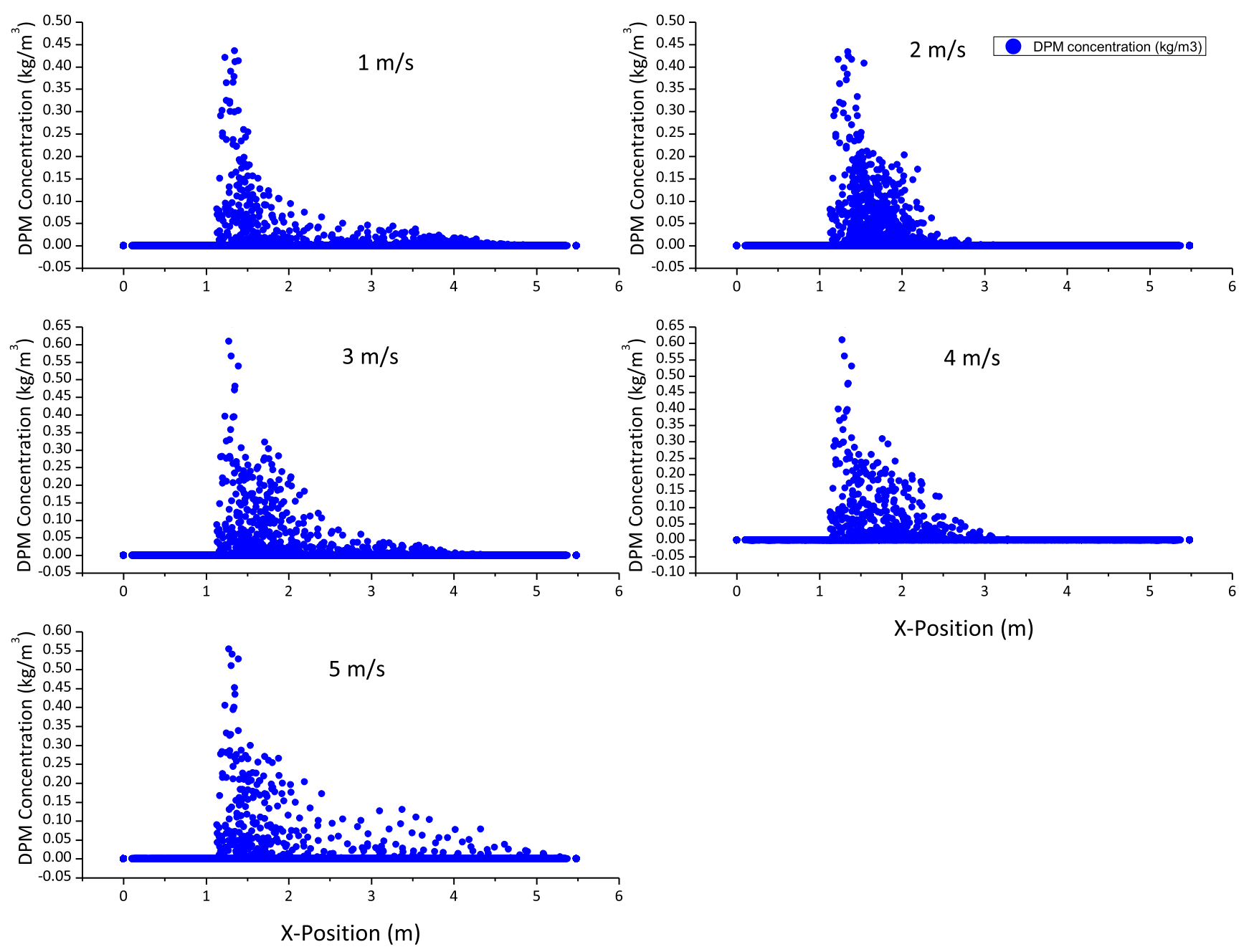

Fig. 3 a Concentration maps showing the effects of air dynamics on sneeze droplets transport (X-position), at air velocities of $1-5 \mathrm{~m} / \mathrm{s}$. (Sneeze droplets size distribution: $0.5-12 \mu \mathrm{m}$ ). b Concentration maps

showing the effects of air dynamics on cough droplets transport (Xposition), at air velocities of $1-6 \mathrm{~m} / \mathrm{s}$

However, depending on air conditions, the small droplets not screened by masks could as well force their ways into the immediate air at low concentrations. On an average air velocity of $2 \mathrm{~m} / \mathrm{s}$, the concentrations were reduced as the flow rate of cough droplets decreased from 1.0 to $0.1 \mathrm{~kg} / \mathrm{s}$ due to the use of masks. In addition, face screens that are without adequate filters may be discouraged as these kinds of barriers would only change the direction of particle dynamics without necessarily reducing its concentration. The corresponding DPM concentration maps at different mask efficiencies are presented in supporting information (S5).

\section{Sneezes and cough droplets would transport differently}

Given the same air flow condition, it was found that distances travelled by sneezes and cough droplets are different, as well as the residence times of their particles as they remain in air. Noting that sneezing can produce as many as 40,000 droplets of $0.5-12 \mu \mathrm{m}$, expelled at a velocity of $100 \mathrm{~m} / \mathrm{s}$, a cough can generate about 3,000 nuclei, the same number as talking for 5 minutes [16]. Large droplets could have shorter residence time in the air while smaller sizes of droplets from infected persons may remain suspended in the air for some time. Cough parcels could reach 3000 droplets released at $10 \mathrm{~m} / \mathrm{s}$. In essence, respiratory maneuvers (such as breathing, speaking, coughing) in human expired droplets could influence the transmission to other persons [27]. In the present DPM numerical study, sneezes have been found to traverse further path length than the cough droplets under the same air flow $(5 \mathrm{~m} / \mathrm{s})$ as shown in Fig. 5a-d.

It is normal that concentrations are higher with sneeze droplets than cough due to parcel concentrations in their release sources, but residence times of cough particles are higher 
b
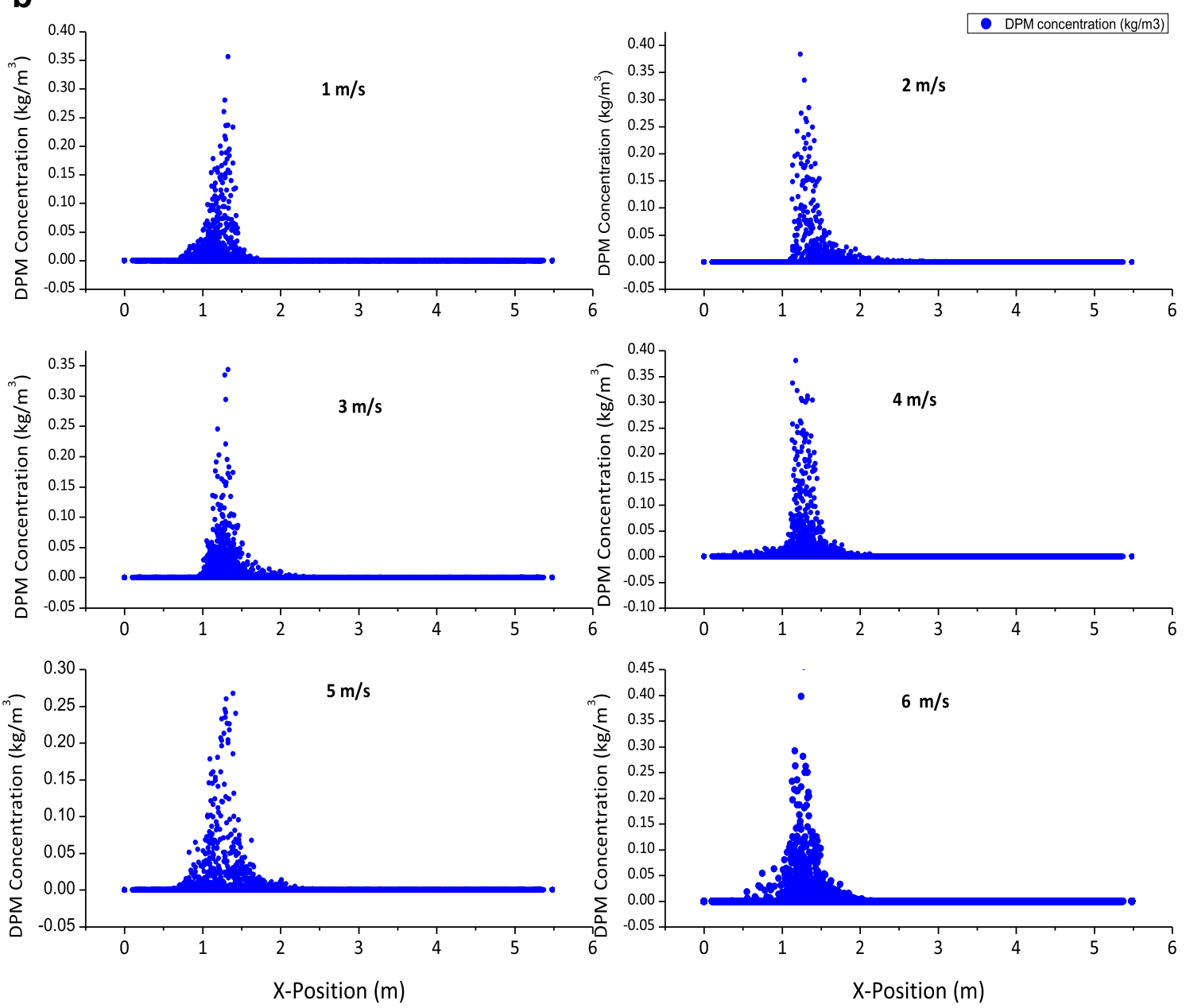

Fig. 3 continued.

than in sneeze particles making cough materials to remain suspended in air at longer times (Fig. 5e, f). This also indicates that large particles tend to fall close to the source of agrees with an established. Though the air velocity of $5 \mathrm{~m} / \mathrm{s}$ is representative of forced convection scenarios under AC systems, fans or similar operations, similar observations can be made with free convection (at lower air velocities - Sect. 3.1). The particle tracks (Fig. 5a, b) show that sneeze droplets due
Fig. 4 Mask efficiencies in reducing the transmission of aerosolized cough/sneeze droplets carrying SARS-CoV-2 virus released by infected persons

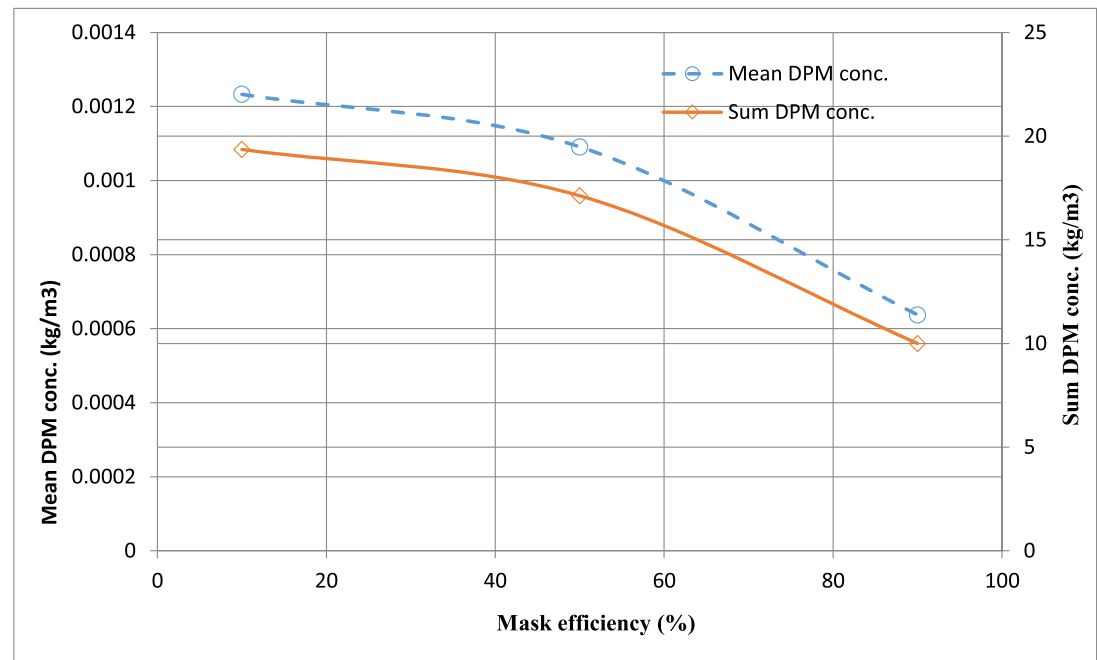



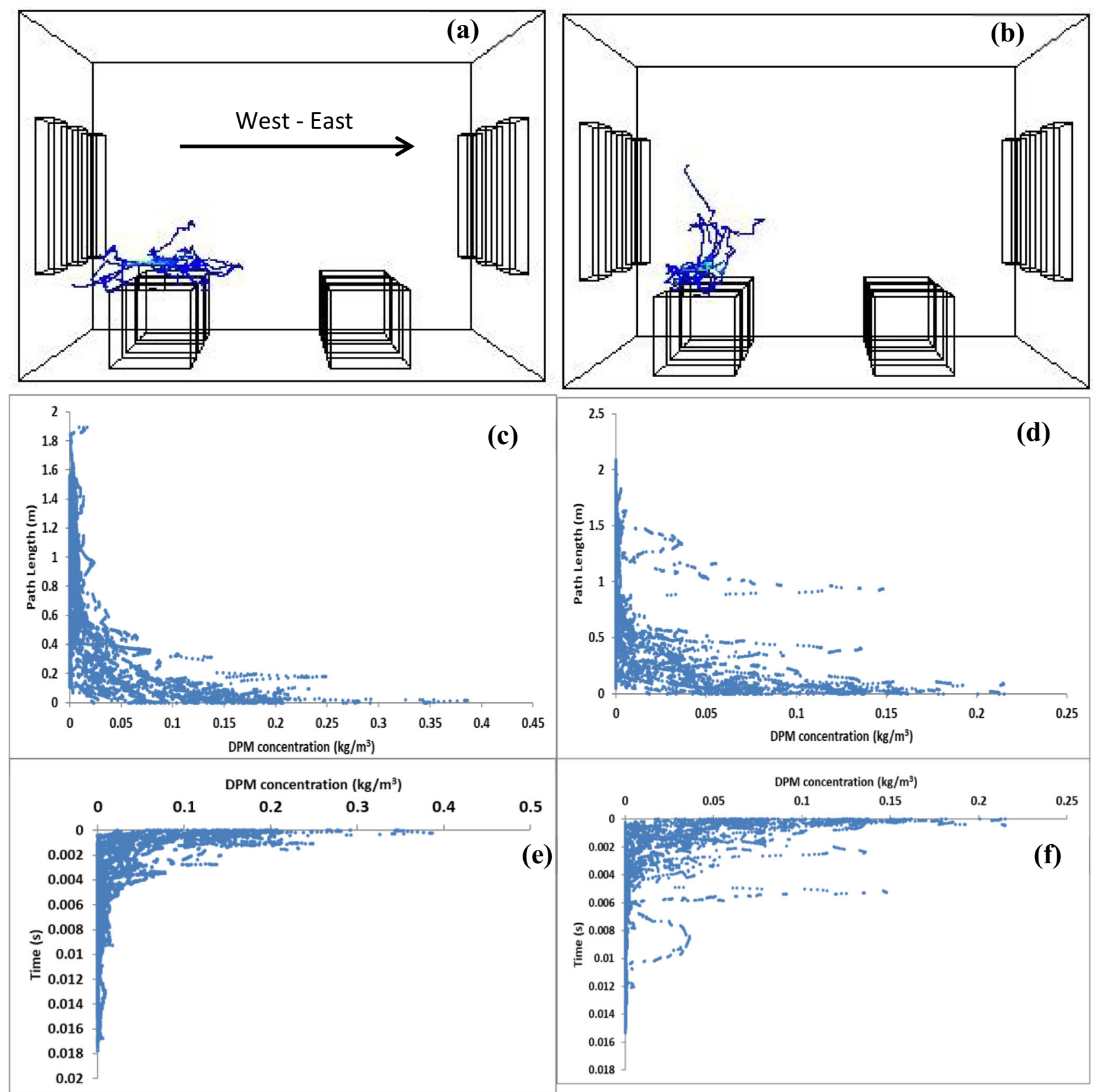

Fig. 5 The 3-D particle tracks, path length, and residence time concentration maps for (a), (c) \& (e) cough droplets, and (b), (d) \& (f) sneeze droplets, respectively. (Flow rates $=1 \mathrm{~kg} / \mathrm{s}$ )

to their larger sizes $(0.5-12 \mu \mathrm{m})$ and higher relative velocity $100 \mathrm{~m} / \mathrm{s}$ (compared to air $-5 \mathrm{~m} / \mathrm{s}$ ) tend to transmit further in the direction of release than cough droplets $(10 \mathrm{~m} / \mathrm{s}, 0.31 \mu \mathrm{m})$ which rather spread quickly in all directions.

\section{Propositions based on DPM model results}

The dynamics of airborne transmission of SARS-CoV-2 through aerosolized cough and sneeze droplets is strongly nonlinear as the particle properties showed complex relationships with the air flow (Fig. 6). Nonetheless, a number of inferences can be made from the DPM simulation results.

\section{How long are droplets able to stay in the air?}

Although transient DPM simulations were not accomplished in this study due to computational demands, the steady-state results could suggest that aerosolized forms of cough/sneeze 
Fig. 6 Nonlinear complex relationships between air velocity and properties of cough/sneeze droplets in the indoor environment

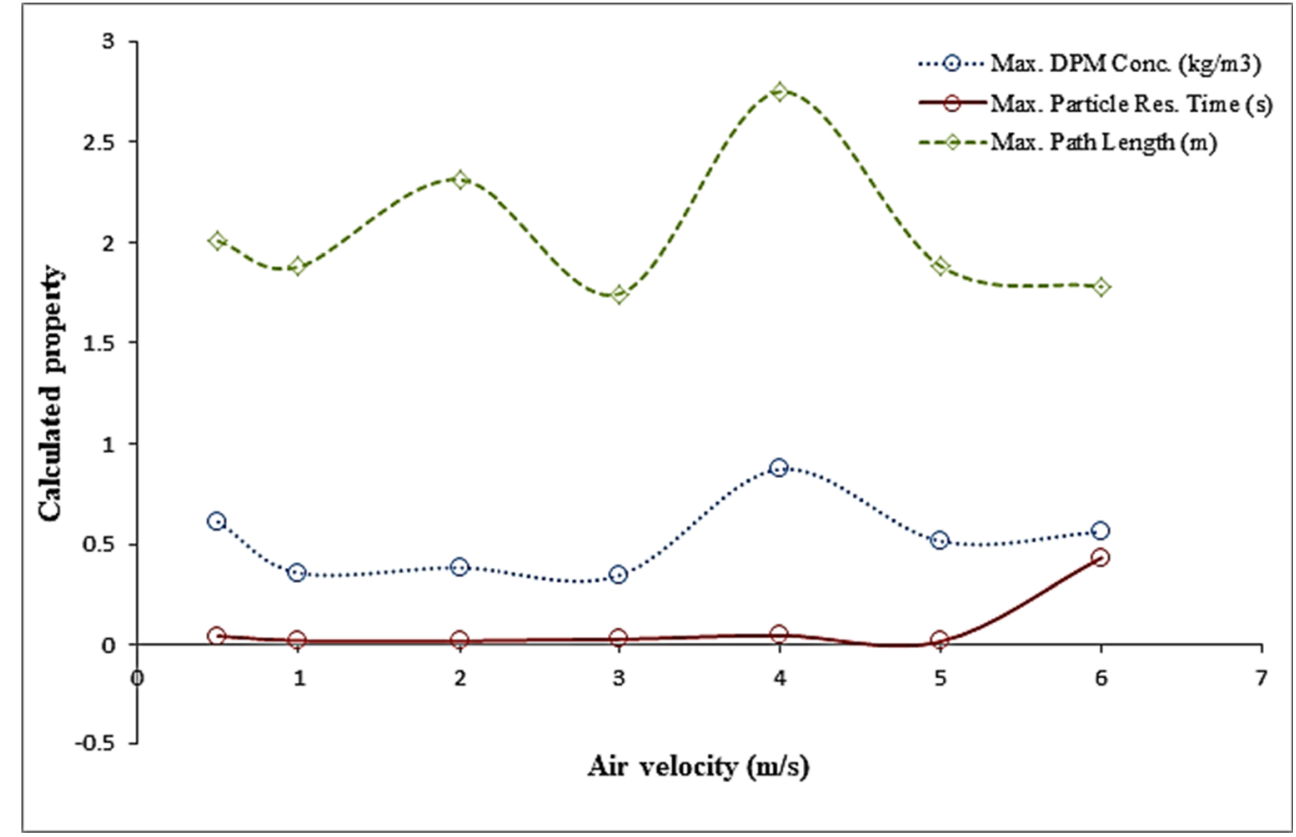

particles are able to remain suspended in the air as long as they travel, and with their dynamics being dictated by the air flow conditions in the environments (Fig. 7).

For as long as the air dynamics permit, the particles are found in the air but their concentrations could reduce as they leave with the exiting air. These residence time observations are different from those reported for a closed, stagnant air environment, where the droplets disappear within 8 to $14 \mathrm{~min}$ [28]. The particle residence time shows the time elapsed by the particles in the trajectory. The residence time of particles suspended in the air is directly proportional to the path length, i.e. the more particles are able to travel along their path, the longer their residence time in the air. The smaller droplets would understandably have longer residence time than the larger droplets [29, 30].
Fig. 7 Transport of cough droplets at air velocity of $1 \mathrm{~m} / \mathrm{s}$ showing (a) \& (b) 3-D concentration maps at residence times of (c) $0.0215589 \mathrm{~s}$ (100 iterations); and (d) $0.0533417 \mathrm{~s} \mathrm{(2,000} \mathrm{itera-}$ tions). Max. Path length: $1.88 \mathrm{~m}$; $2.32 \mathrm{~m}$, respectively
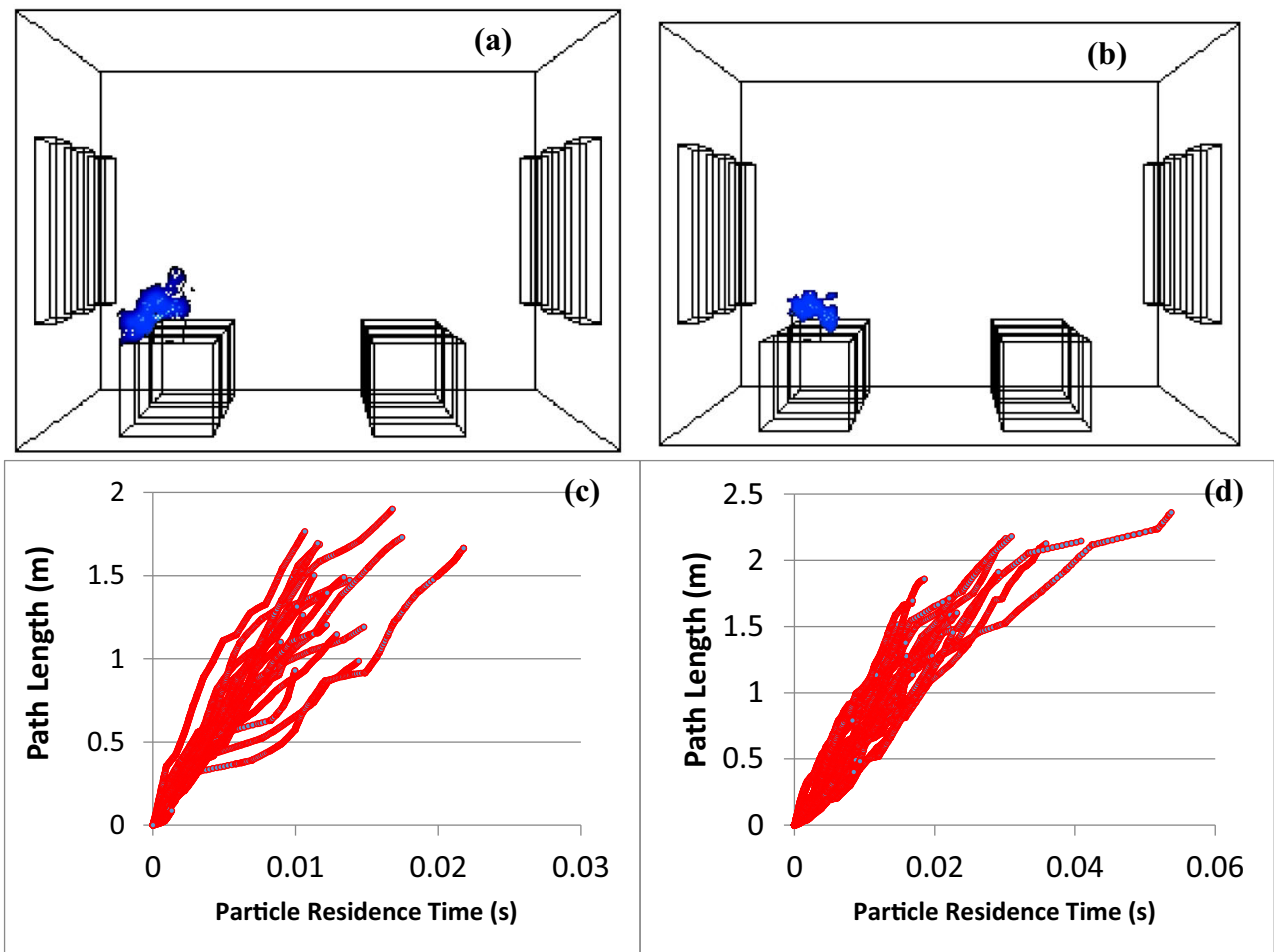


\section{How far could sneezes or cough droplets travel in the air?}

The role of cough and sneezes expired droplets in transmitting SARs-CoV- 2 has been a subject of debate among researchers [30-32]. Air dynamics of aerosols expired in indoor environment remain complex. Determining the absolute distance travelled by cough and sneeze droplets is important to formulate preventive and control measures. Depending on the air dynamics, some sneeze and cough droplets were found at about $4.6 \mathrm{~m}(15 \mathrm{ft})$ and $2.28 \mathrm{~m}(7.5 \mathrm{ft})$ distance from the source of release (supporting information S6 and S7) under normal indoor air flow of about $1 \mathrm{~m} / \mathrm{s}$. The particle tracks were obtained in single pulse mode which sets the pulse mode to release a single wave of particles.

While it is possible that droplets could travel further than the values obtained in the present study as conditions of air dynamics are varied, the results obtained in this work are consistent with values reported in other studies $[2,5]$. Expiratory droplets composition, age and health status of individuals may affect the flow, distance travelled and size distribution of expired droplets [33]. Figure 7 showed that distance travelled by cough droplets at $1 \mathrm{~m} / \mathrm{s}$ air flow could increase (from 1.88 to $2.32 \mathrm{~m}$, or more) with time. However, some contrary observations have also been reported in previous works. For instance, Faridi et al. [32] showed that COVID-19 is not transmitted by airborne route; the bioaerosols were not detected at 2-5 $\mathrm{m}$ distances. Though, real experimental observations may be preferred in investigating whether COVID-19 is airborne, the procedure and circumstance used in the work of Faridi et al. [32] would limit the applicability of their findings to specific conditions.

\section{Keeping social or physical distance: $1 \mathrm{~m}, 2 \mathrm{~m}, 4 \mathrm{~m}$, or more, which way to go?}

An absolute distance to which the SARS-CoV-2 virus could travel is not known. Study conducted by Dbouk and Drikakis [30] opined that $2 \mathrm{~m}$ distance suggested for the social distance recommendation may be grossly insufficient as expired droplet particle could reach up to $6 \mathrm{~m}$. Shafaghi et al. [34] showed that droplets expired by infected person could travel between 4 and $7 \mathrm{~m}$. The study [34] posited that transport dynamics of expired droplets may be complicated by the position and the motion of infected person. Thus, the observance of physical or social distancing could be relative, depending on the circumstance. It is pertinent that policy makers delineate between the several cases that could obviously be determined by particle air dynamics. Taking into consideration the possibility of airborne transmission of SARS-CoV-2 virus would mean introducing improved protocols/guidelines to reduce the risk of the virus spread. Indoor microclimatic parameters such as ventilation strategy, relative humidity and air temperature have been found to affect the concentration level and transport patterns of indoor airborne aerosols $[8,35,36]$.

\section{General ventilation systems: public transports and Safety of essential workers}

With airborne transmission, frontline health workers and security agents enforcing lockdown orders are at greater risk. Persons driving inside their own vehicles may imagine that cough droplets or sneezes which are carrying infectious dose of SARS-CoV-2 from an infected person at close distance outside their vehicles could get into their cars. As the virus could spread through ventilation systems in passenger vehicles, the role of ventilation in preventing its spread should be well-defined. At present, various control measures are being suggested to reduce the infection risks by addressing several extant procedures in operations and design [17-19], including the need for reengineering of ventilation systems. The use of mask and the grade of mask to be used by various categories of essential workers should be encouraged and enforced to safeguard them and reduce spread.

\section{Connection of airborne transmission with contact routes}

The transmission of SARS-CoV-2 virus by direct or indirect contacts with contaminated objects/surfaces have been well documented. There are evidences of possible wall contamination during air transport of virus-laden droplets as obtained in the DPM model results of the present study. Aside sneezing and coughing, studies have shown that the virus could be expired through breathing and talking. However, higher drag force exerted while sneezing could promote the increase in residence time of expired aerosols [34]. The patient masks could also contain exhaled droplets and oral secretions, implying an outright and absolute discouragement to the transfer and reuse of face masks. It is therefore pertinent to routinely disinfect masks before discarding them.

\section{Conclusion}

Coupled discrete phase models of aerosols transport in indoor air were implemented to investigate the aerodynamics of SARS-CoV-2 virus-laden cough droplets and sneezes. It was found that virus-laden droplets could travel up to $4.6 \mathrm{~m}$ or more away from the source of release; but it was not ascertained whether these concentrations were in infectious doses. The residence times of particles also showed that droplets could remain suspended in air for some time, and implications of these observations on the existing guidelines for reducing the risk of SARS-CoV-2 were discussed. The results from this study have given useful insights into indoor dynamics of SARS-CoV-2 and could serve as a guide for the design 
and the setting of reasonable precautionary measures needed to minimize the spread. The suggestions given therein will benefit governments at all levels and relevant stakeholders in curtailing the spread of the pandemic.

Supplementary Information The online version contains supplementary material available at https://doi.org/10.1007/s40201-020-00606-5.

\section{Compliance with ethical standards}

Conflicts of interest/Competing interest The authors confirm no conflict of interest associated with this publication.

\section{References}

1. WHO. Coronavirus disease (COVID-19) Situation Report - 154, 22 June 2020, 10:00am CEST: World Health Organization; 2020. Available from: https://www.who.int/docs/default-source/ coronaviruse/situation-reports/20200622-covid-19-sitrep-154.pdf? sfvrsn=d0249d8d 2. Accessed 15 July 2020.

2. Guo Z-D, Wang Z-Y, Zhang S-F, Li X, Li L, Li C, et al. Aerosol and surface distribution of severe acute respiratory syndrome coronavirus 2 in hospital wards, Wuhan, China, 2020. Emerg Infect Dis. 2020;26(7):10.3201. https://doi.org/10.3201/eid2607.200885.

3. Shereen MA, Khan S, Kazmi A, Bashir N, Siddique R. COVID-19 infection: Origin, transmission, and characteristics of human coronaviruses. J Adv Res. 2020;24:91-8. https://doi.org/10.1016/ j.jare.2020.03.005.

4. WHO. Modes of transmission of virus causing COVID-19: implications for IPC precaution recommendations: Scientific brief 29 March 2020. Geneva: World Health Organization; 2020.

5. Morawska L, Cao J. Airborne transmission of SARS-CoV-2: The world should face the reality. Environ Int. 2020:105730. https://doi. org/10.1016/j.envint.2020.105730.

6. Adeniran JA, Sonibare JA, Jimoda LA. Statistical approach for determining the effects of microclimatic parameters on household spray products aerosol deposition. Atmos Pollut Res. 2015;6(1): 21-8. https://doi.org/10.5094/APR.2015.003.

7. Adeniran JA, Yusuf RO, Oke EO. Deposition and coagulation of aerosols from household spray products. Songklanakarin J Sci Technol. 2019;41(1). https://doi.org/10.14456/sjst-psu.2019.25.

8. Adeniran JA, Araromi DO, Yusuf RO, Jimoda LA, Oke EO, Sonibare JA. Analytical modeling of human exposure from shortterm point source releases of aerosols from household spray products. Sci Technol Built Environ. 2019;25(1):83-90. https://doi.org/ 10.1080/23744731.2018.1499383.

9. Ningthoujam R. COVID 19 can spread through breathing, talking, study estimates. Curr Med Res Pract. 2020. https://doi.org/10.1016/ j.cmrp.2020.05.003.

10. Tellier R. Review of aerosol transmission of influenza A virus. Emerg Infect Dis. 2006;12(11):1657. https://doi.org/10.3201/ eid1211.060426.

11. Wong T-w, Lee C-k, Tam W, Lau JT-f, Yu T-s, Lui S-f, et al. Cluster of SARS among medical students exposed to single patient, Hong Kong. Emerg Infect Dis. 2004;10(2):269. https://doi.org/10. 3201/eid1002.030452

12. Yu IT, Wong TW, Chiu YL, Lee N, Li Y. Temporal-spatial analysis of severe acute respiratory syndrome among hospital inpatients. Clin Infect Dis. 2005;40(9):1237-43. https://doi.org/10.1086/ 428735.

13. Li Y, Huang X, Yu I, Wong T, Qian H. Role of air distribution in SARS transmission during the largest nosocomial outbreak in Hong
Kong. Indoor Air. 2005;15(2):83-95. https://doi.org/10.1111/j. 1600-0668.2004.00317.x

14. Yu IT, Li Y, Wong TW, Tam W, Chan AT, Lee JH, et al. Evidence of airborne transmission of the severe acute respiratory syndrome virus. N Engl J Med. 2004;350(17):1731-9. https://doi.org/10. 1056/NEJMoa032867.

15. Li Y, Duan S, Yu I, Wong T. Multi-zone modeling of probable SARS virus transmission by airflow between flats in Block E, Amoy Gardens. Indoor Air. 2005;15(2):96-111. https://doi.org/ 10.1111/j.1600-0668.2004.00318.x.

16. Tang J, Li Y, Eames I, Chan P, Ridgway G. Factors involved in the aerosol transmission of infection and control of ventilation in healthcare premises. J Hosp Infect. 2006;64(2):100-14. https:// doi.org/10.1016/j.jhin.2006.05.022.

17. Viola I, Peterson B, Pisetta G, Pavar G, Akhtar H, Menoloascina F, et al. Face coverings, aerosol dispersion and mitigation of virus transmission risk. arXiv preprint arXiv:200510720. 2020. https:// www.sciencemediacentre.org/tag/covid-19.

18. Liu Y, Ning Z, Chen Y, Guo M, Liu Y, Gali NK, et al. Aerodynamic analysis of SARS-CoV-2 in two Wuhan hospitals. Nature. 2020:1-4. https://doi.org/10.1038/s41586-020-2271-3.

19. Morawska L, Tang JW, Bahnfleth W, Bluyssen PM, Boerstra A, Buonanno G, et al. How can airborne transmission of COVID-19 indoors be minimised? Environ Int. 2020:105832.

20. Meselson M, Guillemin J, Hugh-Jones M, Langmuir A, Popova I, Shelokov A, et al. The Sverdlovsk anthrax outbreak of 1979. Science. 1994;266(5188):1202-8.

21. Sørensen JH, Jensen C, Mikkelsen T, Mackay D, Donaldson AI. Modelling the atmospheric dispersion of foot-and-mouth disease virus for emergency preparedness. Phys Chem Earth Part B. 2001;26(2):93-7. https://doi.org/10.1016/S1464-1909(00)002239.

22. Mao S, Redrow J, Celik IB. Modeling of bio-aerosol transport and dispersion in ventilation room. The Proceeding of Options for the Control of Influenza VI, Toronto, Ontario, Canada. 2007.

23. Khalid A, Scherrer C. Alternatives for reducing the risk of transmission of tuberculosis in a typical hospital clinic in developing African countries. Procedia Comput Sci. 2013;16:853-62. https:// doi.org/10.1016/j.procs.2013.01.089.

24. Park CIP, editor Simulating aerosol movement in experimental chambers using computational fluid dynamics. CSBE/SCGAB 2017 Annual Conference 2017 6-10 August 2017; Canad Inns Polo Park, Winnipeg: The Canadian Society for Bioengineering.

25. Lu R, Zhao X, Li J, Niu P, Yang B, Wu H, et al. Genomic characterisation and epidemiology of 2019 novel coronavirus: implications for virus origins and receptor binding. Lancet. 2020;395(10224):565-74. https://doi.org/10.1016/S01406736(20)30251-8.

26. Arons MM, Hatfield KM, Reddy SC, Kimball A, James A, Jacobs JR, et al. Presymptomatic SARS-CoV-2 infections and transmission in a skilled nursing facility. N Engl J Med. 2020. https://doi. org/10.1056/NEJMoa2008457.

27. Johnson G, Morawska L, Ristovski Z, Hargreaves M, Mengersen $\mathrm{K}$, Chao $\mathrm{CYH}$, et al. Modality of human expired aerosol size distributions. J Aerosol Sci. 2011;42(12):839-51. https://doi.org/10. 1016/j.jaerosci.2011.07.009.

28. Stadnytskyi V, Bax CE, Bax A, Anfinrud P. The airborne lifetime of small speech droplets and their potential importance in SARSCoV-2 transmission. Proc Natl Acad Sci. 2020;117(22):11875-7. https://doi.org/10.1073/pnas.2006874117.

29. Dombrovsky LA, Fedorets AA, Levashov VY, Kryukov AP, Bormashenko E, Nosonovsky M. Modeling evaporation of water droplets as applied to survival of airborne viruses. Atmosphere. 2020;11(9):965. https://doi.org/10.3390/atmos11090965. 
30. Dbouk T, Drikakis D. On coughing and airborne droplet transmission to humans. Phys Fluids. 2020;32(5):053310. https://doi.org/ 10.1063/5.0011960.

31. Dhand R, Li J. Coughs and sneezes: their role in transmission of respiratory viral infections, including SARS-CoV-2. Am J Respir Crit Care Med. 2020;202(5):651-9. https://doi.org/10.1164/rccm. 202004-1263PP.

32. Faridi S, Niazi S, Sadeghi K, Naddafi K, Yavarian J, Shamsipour $\mathrm{M}$, et al. A field indoor air measurement of SARS-CoV-2 in the patient rooms of the largest hospital in Iran. Sci Total Environ. 2020:138401. https://doi.org/10.1016/j.scitotenv.2020.138401.

33. Bahl P, de Silva CM, Chughtai AA, MacIntyre CR, Doolan C. An experimental framework to capture the flow dynamics of droplets expelled by a sneeze. Exp Fluids. 2020;61(8):1-9. https://doi.org/ 10.1007/s00348-020-03008-3.

34. Shafaghi AH, Rokhsar Talabazar F, Koşar A, Ghorbani M. On the effect of the respiratory droplet generation condition on COVID-19 transmission. Fluids. 2020;5(3):113. https://doi.org/10.3390/ fluids5030113.

35. Asadi S, Bouvier N, Wexler AS, Ristenpart WD. The coronavirus pandemic and aerosols: Does COVID-19 transmit via expiratory particles? Aerosol Sci Tech. 2020;54(6):635-8. https://doi.org/10. 1080/02786826.2020.1749229.

36. Adeniran JA, Yusuf RO, Abdulkadir MO, Yusuf M-NO, Abdulraheem KA, Adeoye BK, et al. Evaporation rates and pollutants emission from heated cooking oils and influencing factors. Environ Pollut. 2020;266:115169. https://doi.org/10.1016/j. envpol.2020.115169.

Publisher's Note Springer Nature remains neutral with regard to jurisdictional claims in published maps and institutional affiliations. 